\title{
DENTISTRY IN ENGLAND IN THE 1840s: THE FIRST INDICATIONS OF A MOVEMENT TOWARDS PROFESSIONALIZATION
}

\author{
by
}

\author{
N. DAVID RICHARDS \\ 'It is only the first step which is troublesome'. \\ Marquise de Deffand (1697-1780)
}

THis paper traces early moves during the fourth decade of the last century to bring about an alliance of those practising the art of dentistry. For these persons this was a period of tense struggle and of the emergence of cliques. Dentistry was at this time in the throes of progressing from a state of being an undifferentiated occupation, that is-practice by a lay person as a secondary occupation, to that of being an occupational entity, in which persons began to give themselves exclusively to the practice of dentistry. There were also evolving the first signs of, and claims for, a professionalization for dentistry; for the first time certain dental practitioners began to try to organize themselves together into societies and associations, which would afford dentistry a more exalted and professional position, and which would reform the prevailing chaos in dental matters.

The first half of the nineteenth century saw the emergence of the organized professions, and of the introduction of formal training and minimum standards of admission. In a study of early moves towards the emergence of dental surgery as a separate professional entity, it is therefore relevant to remember that other professional occupations, and particularly the medical and surgical professions, were themselves for many years only superficially organized-largely perhaps a result of the manner in which the population had developed. Until the end of the eighteenth century the population remained relatively small and was widely distributed in selfcontained rural communities. The nineteenth century saw tremendous increases in the population and a move away from the country into the towns. Hitherto specialists such as physicians, surgeons, dentists and apothecaries were either geographically or socially isolated from each other, or were too few in number to require or make possible any regulation of competition or the introduction of codes of practice. There was no legal restriction to prevent the unqualified or untrained practitioner from offering his services to the public. It was indeed not until after some years of urbanization that medicine itself became organized; in the circumstances it is therefore not surprising to find that dentistry, evolving as it did as a paramedical speciality, was not to become organized until the second half of the nineteenth century. ${ }^{1}$ Before the passing of the

1 For a description of the evolution of professionalism during this period see G. L. Millerson, The Qualifying Associations, London, 1964. The development of the medical profession in the social context is discussed by S. W. F. Holloway, 'The Apothecaries Act, 1815: a reinterpretation', Med. Hist., 1966, 10, 107-29 and 221-36, and 'Medical education in England: 1830-1858: a sociological analysis', History, 1964, 49, 299-324. 


\section{N. David Richards}

1858 Medical Act, which provided for the creation of the General Council for Medical Education and Registration, the line of demarcation between qualified and unqualified medical practitioners was extremely difficult to trace, and there was very little evidence available to inform the public who was and who was not qualified to practise medicine or surgery.

It is in this dark background formed by ignorance, empiricism and lack of organization that we should view dentistry about the year 1840 . Judged by presentday standards dentistry as practised during these years presents a very bleak and disappointing picture; it is as well to remember however that the early history of many professions is enveloped in an aura of quackery, charlatanism, public apathy and lack of scientific knowledge-very often, initial developments follow, not as a result of group pressures, but rather from isolated pleas for progress and reform from certain far-sighted practitioners, acting quite independently and speaking for themselves. The development of dental surgery within this country has very much followed this latter pattern; the initial suggestions for reform emanated not from a body of dentists but rather from individuals who were expressing their own personal convictions of the need, for the good of both the profession and the public, to remedy existing evils and faults. That these were lone voices is evidenced by the subsequent lack of supporting statements and correspondence in the contemporary literature; it is, for example, significant that many of these individual pleas for reform failed to induce a flood of letters or opinions and seem to have been received in stony silence by the vast majority of dentists. As a result no concerted action followed immediately upon the publication of these ideas.

During the early part of the last century those who practised dentistry in this country were for the most part uneducated men, and charlatanism, the offspring of ignorance and presumption, was rampant. Blatant advertisements were used to extol the skill of the individual dentist - together with claims of miraculous ability which was available at temptingly low fees-these were used to lure the unsuspecting public. The public press contained many alluring advertisements concerning new methods of treatment-brochures about the care of the teeth were circulated and were used to advertise where treatment could be obtained. There was no unity, organization, or code of ethics, and 'the overwhelming proportion of dentists at this time were mere tradesmen and sadly lacking in all scientific knowledge. ${ }^{2}$ In addition, there was no accepted standard of education and, as a result, success, if not due to scientific knowledge or technical ability, was often due mainly to brazen effrontery. Many dentists practised in shops which were garishly decorated with dental appliances or, very often, with human teeth. Improvements or discoveries in dentistry were guarded and kept secret and used mainly for the individual's own personal advancement. 'Dentistry in fact very much resembled the border warfare of feudal times. Every man was fighting for his own hand.'3 It seems remarkable how little the dentists of this period knew of each other and how strictly each guarded the techniques of his own practice. There was at this time no widely circulated and exclusively dental periodical

2J. Lewin Payne, 'Milestones in the history of British dentistry', Brit. dent. J., 1924, 45, 138.

3 A Hill, The History of the Reform Movement in the Dental Profession in Great Britain, London, 1877, p. 6. 


\section{Dentistry in England in the 1840s}

literature and there were indeed very few means of communicating with fellow practitioners. Dentistry was almost wholly unorganized and it would appear that it tended to suffer from public ill-repute; in the circumstances it is perhaps as well to remember Dante's lines from the Divine Comedy-'let us not speak of them but look and pass on'.

There were nonetheless some visionaries who were prepared to devote time and energy towards raising the status of the profession. One such man was Edwin Saunders, who, at the age of 22, in 1836 examined the teeth of children in orphanages. At this time the conditions of children working in factories was something of a scandal, since parents often attempted to make their children appear older than they were. Following dental examinations of some 1,046 children he was able to draw up tables showing the age of eruption of the teeth between the ages of 9 and 13 and to reveal conditions which could not be cloaked. He addressed his results to Members of Parliament because he wished to 'facilitate the operation of whatever enactments shall be determined upon by the legislature in relation to children employed in factories'.4 The previous Factories Acts had been rendered practically inoperative since they laid down no precise criteria by which a child's age could be ascertained. Some inspectors had included criteria based on stature, but Saunders insisted that a measure of maturity and not size was required. He considered that an estimate of age based on the development of the teeth would make fraudulent deception impossible; this is perhaps the earliest evidence in a public document to stress the importance of the teeth in child welfare.

Dentistry was seen at this time as being principally a relief of pain (through extraction) service; a contemporary dictionary definition of a dentist was that of 'one who cleans and extracts teeth'. ${ }^{5}$ Dentists were clearly held in no high esteem-the following quotation is to the point-'treatises on teeth appear at least once a quarter, and dentistry, as we find it called, is growing into a profession which numbers nearly as many members as surgery. Great rogues many of them are'. ${ }^{6}$

There appeared in 1839 the very first journal devoted exclusively to the practice of dental surgery-the American Journal of Dental Science. One contributor to this journal stated his view very strongly - our calling is disgraced by charlatans, who by ignorance, recklessness and ostentation have polluted the temples" country so too in North America, it seemed, was dentistry beset by the nefarious practices of many of those who claimed to be dentists. The solution, provided by American dentists, was that strenuous efforts were 'made on the other side of the Atlantic to rescue a most useful, though perhaps humble, branch of surgery from the depth of degradation to which it has been reduced'. ${ }^{8}$ These efforts culminated in 1841 in the institution of a dental degree-the Doctorate in Dental Surgery (D.D.S.)which was conferred initially by the Baltimore College of Dental Surgery. Commenting on this development, the Lancet remarked 'we heartily desire that some such

' E. Saunders, Teeth, a Test of Age, Considered with Reference to Factory Children, London, 1837. [Reprinted in Amer. J. dent. Sci., 1846-7, 7, 330-75].

s Quoted by J. Menzies Campbell, Dental Record, 1946, 66, 78.

- Quoted by Campbell, op. cit., 82 .

'Tait's Edinburgh Magazine, 1838, 5, 197- quoted by J. Menzies Campbell in Dentistry Then and Now, Glasgow, 1963, p. 245.

Letter from W. H. Lintott, Lancet, 1840-1, II, 597. 


\section{N. David Richards}

anxiety for improving this branch of the profession [surgery] in this country should be evinced'.?

Access to dental treatment did not appear to be solely the prerogative of the rich classes for, during these years, several moves were already afoot to provide dental services for those who could not afford the dentist's services. About 1840 the London Institution for the Diseases of the Teeth was founded under the able superintendence of Edwin Saunders, James Snell and W. Harrison, three of the most eminent practitioners of the time. For a period of about five years, at a surgery in Windmill Street, off Tottenham Court Road, this institution afforded dental services to the poor of the district. It is not clear what causes led to the closure of this charitable foundation and for some years afterwards no further attempt appears to have been made to organize a similar one. The poor were compelled to seek the advice of those dentists who were willing to devote some portion of their time to gratuitous advice and treatment. One such practitioner was Alexander Nasmyth, who 'regularly reserved part of each day for gratuitously treating the necessitous poor; yearly about 1,700 persons availed themselves of his kindness'. ${ }^{10}$ Another prominent dentist who gave his services was John Tomes, who wrote thus to one of his friends: 'I take no fee less than $f 1 \mathrm{ls}$. $0 \mathrm{~d}$. professedly unless the patient come by the recommendation of some friend who tells me they are poor. I purpose working at extraction from nine until eleven every morning at poor non-paying patients'.11

A vivid and lucid picture of dentistry as practised during these years has been provided by Alfred Hill in his History of the Reform Movement in the Dental Profession in Great Britain. Writing of this period, Hill noted that dentistry offered tempting facilities to uneducated individuals to practise it-'the great bulk of dentists practising in the United Kingdom, of whom there were some hundreds, were as a class, sadly lacking in scientific knowledge . . . Many had entered upon the practice of dentistry as a means of obtaining a livelihood only, and had not hesitated to combine with it a trade of some sort or other, in order to secure a larger emolument than dentistry, per se, would bring them.' ${ }^{\text {22 }}$ Not all practitioners however were like this and there were some who strove to upgrade the calling-'like lofty peaks in a mountain range they showed clear and bright above the others; but they were the great and glorious exceptions to those around them. At their base lay the broad valley of empiricism, steeped and bathed in the mists of ignorance and claiming recognition by the noise of its own impudent pretensions'.18 There was little knowledge of the numbers or identity of those who practised dentistry; it is however known that a crucial role was at this time played by the chemist-'people flocked, especially the poor, to the chemist for help and deliverance from torture [of toothache], and at a nominal cost to them he was prepared to operate'. ${ }^{14}$ That chemists developed a lucrative side to their business from both the extraction of teeth and also from the sale of cleaning materials, tooth powder and dentifrices, is supported by Wardroper's reference to the fact that a chemist he knew who practised in a large country town received $£ 200$ per year by drawing teeth at a shilling each (i.e. he extracted 4,000 teeth a year). ${ }^{15}$

\footnotetext{
- Lancet, 1843, ii, 74.

10 Quoted by Campbell, 1963, op. cit., p. 248.

11 Quoted by Sir Zachary Cope, Sir John Tomes-Pioneer of British Dentistry, London, 1961, p. 12.

12 Hill, op. cit., p. 2.

16 W. Wardroper, The Structure, Diseases and Treatment of the Teeth, London, 1838, p. 9.
} 


\section{Dentistry in England in the 1840s}

Not only in the towns was dentistry frequently practised as a side-line; in the country districts it was often incorporated as a side-line to the trade of blacksmith, who very often would have initially forged instruments for other persons and then perhaps at a later date commenced practice himself, as an extractor of teeth, using his own instruments. Many dentists at this time were itinerant-moving around from town to town to claim mystic powers for their pills and powders. They frequently performed their services in public, using loud and strident music as a background to drown the cries from their patients. It appears that the mass of the population knew but little of dental attention except at the hand of the tooth-puller-'an indiscriminating public offered temptations too strong to be resisted by the rapacious and unprincipled empiric pretending to practise what to a very large extent was considered to be a semi-mysterious art. Opportunities abounded for throwing dust in the eyes and the occasion was diligently utilised ${ }^{16}$ The charlatanism and empiricism of many who called themselves dentists did not however pass completely unnoticed-a letterwriter to the Lancet suggested in 1839 that 'perhaps no species of empiricism has ever been carried to so great an extent with impunity as that practised at the present-day by the advertising (self-styled) surgeon-dentists. With most unblushing and shameless effrontery do these persons, through the medium of the public prints, profess to perform utter impossibilities'. ${ }^{17}$

Lacking a common centre, bond of association or union, the vast majority of dentists practised exclusively and primarily for their own individual interests. Not all dentists were however indifferent to the future of their specialism-many practising dentists had achieved the positions they held only after long effort and years of close and patient study. To such men the habits and practices of the uninitiated and uneducated were repulsive-what was lacking was a leader to fuse them together. No single amalgamation of professional interests evolved largely because dentists were basically divided into two quite separate sections-on the one hand there was a small group of educated men who held medical and/or surgical qualifications, and on the other a large group of uneducated and unqualified persons who attracted clients by blatant advertising and claims to provide an instant and miraculous relief from dental troubles. The higher class of practitioners were conscious of a wide and deep gap which separated them from the rank and file. In both factions bitter jealousies abounded keeping men apart. There was nonetheless, as is evident from a reading of medical and dental journals of this period, all the time developing a growing feeling that something should be done to protect dental surgery and to lessen the grievances which the public was suffering at the hands of an ever increasing horde of ignorant and unscrupulous practitioners.

The first ripples on the troubled waters appeared in 1841 when J. L. Levison and George Waite, acting quite separately, both made strong pleas for the need to develop a more positive approach to dentistry. In a letter published in the Lancet Levison suggested the formation of a Faculty of Dental Surgeons, the framing of a code of ethics and the institution of a system of examinations to provide for a diplomaqualification, for, as he remarked, 'very shortly something will be necessary to give

16 Hill, op. cit., p. 16.

${ }^{17}$ Letter from J. K. M., Lancet, 1838-9, ii, 112. 


\section{N. David Richards}

the public confidence in dental practitioners' ${ }^{18}$ Waite's ideas were set out in a pamphlet-An Appeal to Parliament, the Medical Profession and the Public on the Present State of Dental Surgery. He drew attention to the conditions of dental practice and suggested eradicating existing evils, safeguarding the public and bringing about a higher and more uniform standard of dental practice. In Waite's own words: 'It is quite an anomaly that so important a branch of the Medical Profession as Dental Surgery should so long have remained unprotected; that the abuses to which the public has been so long exposed should have been quietly passed over; and that the regular and respectable practitioners should have patiently submitted to the grievances under which they have been oppressed without seeking redress in the proper quarter'. ${ }^{19}$ He also drew attention to the present state of dentistry-'I purpose showing the necessity of the Legislature and the Medical Profession recognising this [dentistry] as a legitimate branch of the science, and that no persons be permitted hereafter to practise without having undergone examination by one or more censors of the Royal College of Surgeons. As it is now dentistry can be considered no profession; a person, however illiterate and uneducated, may commence practice; and society being unprotected, there is no reason why he may not be consulted: in which case, there being no guarantee that he is professionally competent, he may operate on a tooth in the neighbourhood of an incipient malignant tumor and thereby do the greatest mischief' ${ }^{20}$ His purpose and his plea for parliamentary intervention are made clear'to me it appears extraordinary that in this great capital, the most enlightened in Europe, and in this age of advanced science, such charlatanism should not directly be checked; and $I$ have no hesitation in saying that the rank of the profession and interests of society demand legislative protection'. ${ }^{21} \mathrm{He}$ continues: 'Public voice will I am sure aid my efforts'. ${ }^{22}$ - a view, which in the light of the lack of any immediate action, appeared to be wishful and over-optimistic.

Waite's pamphlet provides a lucid picture of the opportunities offered to the impostor to practise dentistry-'unprincipled adventurers, workboys from unscientific mechanists, decayed tradesmen, vendors of quack medicine, even old clothesmen, and others assuming false or foreign names have dispersed themselves throughout England, and regardless of any feeling of truth, put forth advertisements professing impossibilities' ${ }^{23}$ He refers to the frequently dire effects of unskilled treatment and to the need for the introduction of both a code of laws to govern the practice of dentistry, and also of a scale of fees-his support for the creation of a professional association is made clear: 'I shall feel proud to join any professional men in promoting any institution which in the absence of support from the Legislature may form the germ of a society which at some future date may obtain a Royal Charter'. ${ }^{24}$

Waite also notes the lack of professional contacts or fellow feelings between those who called themselves dentists-'amongst dentists, at present, no cordiality exists; first-rate science has been confined to a limited few. ${ }^{25} \mathrm{He}$ compares the situation with that facing the medical profession - 'turning aside from these considerations

18 Lancet, 1840-1, i, 598.

10 G. Waite, An Appeal to Parliament, the Medical Profession and the Public on the Present State of Dental Surgery, London, 1841, p. 3.

${ }_{20}$ Waite, op. cit., p. 4.

23 Waite, op. cit., pp. 8-9.

21 Waite, op. cit.; p. 6.

24 Waite, op. cit., p. 19.
22 Waite, op. cit., p. 7.

${ }^{25}$ Waite, op. cit., p. 9. 


\section{Dentistry in England in the 1840s}

to those feelings which exist between dentists, it is impossible to do so without the deepest regret at the heterogeneous mass arrogating to themselves the professorship of the art'.26

The public was suffering, in Waite's opinion, as a result of malpractice on the part of unscrupulous and unprincipled charlatans, and it was therefore, he considered, 'the duty of the Legislature to protect the public more especially against any system of imposition which can deteriorate the health of society'. ${ }^{27}$ To remedy this state of affairs, he suggested that the Royal College of Surgeons should institute a board of officers elected from its dental members to issue diplomas to persons who had successfully taken certain examinations-'The College of Surgeons might easily nominate a board of officers from Dentists, members of their College, who might issue diplomas to such dentists as undergo competent examinations and act as Censors appointed for that purpose; and hereby they would place an important branch of the profession on a high footing which would contribute materially to the welfare and health of the community'. ${ }^{28}$

Waite's pamphlet led to the first real breaking of the icy apathy which surrounded dentistry-it is however impossible to assess how widely it was distributed, read or discussed. It seems abundantly clear that, for the time being anyway, these ideas fell upon deaf ears and that Waite's efforts to remedy matters appear to have been unsuccessful. Neither Parliament, the medical profession nor the public brought about any of the changes advocated-indeed it took almost another twenty years to get a diploma and a further eighty years to get a prohibition of unregistered practice. Waite's ideas were perhaps handicapped by the fact that he appears to have been writing as an individualist rather than as the spokesman for any group of interested parties. No immediate action followed and, as Hill puts it, 'the dark waters of ignorance and prejudice of that day seemed to flow on untroubled as before, and no light was yet on the horizon'.29

Woodhouse has produced a contemporary picture of how a new recruit to the dental ranks started his work. He himself commenced his apprenticeship in 1842at first he worked at the bench and then moved into the surgery and watched his sponsor at work. After three months he took over the gratis patients, and then graduated after one year to looking after the private patients when his principal was away. He comments that at this time 'all dentists jealously guarded their modes of practice and few knew other members of the profession for each worked as a hermit in his cell'.$^{30}$ The reminiscences of other practitioners underline the isolation in which the majority of dentists worked. What wonder then that the moves towards an improvement in dental matters were so slow coming about? Before the introduction in 1843 and 1844 of the first dental periodicals to appear in this country, there were precious few opportunities presented for the exchange of dental, scientific and professional information. These new journals were largely the result of efforts on the part of James Robinson, who, in 1842, had been the first to attempt to form a dental society, and who had also earlier contributed to the American Journal of Dental Science. This further effort to bring about a union of dentists was abortive largely

\footnotetext{
Ibid.

27 Waite, op. cit., p. 15.

28 Waite, op. cit., p. 16.

2o Waite, op. cit., p. 19.

so A. J. Woodhouse, J. Brit. dent. Assoc., 1897, 18, 23.
} 


\section{N. David Richards}

owing to the apathy and jealousy prevailing among the practitioners of this timethese forces proved too powerful for Robinson and his scheme had to be abandoned.

The next major scheme to place dentistry on a new footing owes its origins to a bill to be introduced by Sir James Graham, the Home Secretary, to regulate the medical profession. ${ }^{31}$ Before bringing before Parliament his bill which suggested a uniform and centralized system of granting degrees and licences to practise medicine, he instructed the Council of the Royal College of Surgeons that it was a suitable time for it to draft a new charter. A leading dentist of the time, Arnold Rogers, was acquainted with Major Graham, the brother of the bill's sponsor; perhaps through this friendship Rogers' interest in the bill was stimulated, for he came to realize that the introduction of certain clauses in the bill might profit the dental cause. A small group of prominent dentists met on 4 March 1843 at Rogers' home and determined to use this occasion to obtain legal recognition for the practice of dental surgery. The following day, Arnold Rogers and Charles Stokes representing this small group approached Anthony White, the President of the Royal College of Surgeons, and asked that the Council should seek the necessary powers in their new charter to establish a dental department, and a diploma qualification in dental surgery. Mr. White appears to have received the deputation with some degree of tartness, asking them first if the proposed diplomates would participate in the government of the College-the fear was generated that dentists might claim a share in the government of the college, particularly so since the college was at that time considering the establishment of the Fellowship in Surgery. It is indeed important to understand that the profession of surgery was itself at this period in a formulative stage, and trying to establish its own standards of education-in many ways then the approach of the dentists may be seen as premature. The deputation instantly disavowed any intention of the diplomates being concerned in the government of the college-Hill adds that "had there been the slightest trace of such a desire ... the interview would have been abruptly terminated'. ${ }^{32}$ The President considered 'the members of the college practising exclusively the dental profession were in strictness seceders' ${ }^{33} \mathrm{He}$ begged them not to memorialize the college, but rather to address a letter as members of the body of surgeons to their fellow members.

Further meetings of this small coterie of men representing the leading talent of the dental profession followed and letters were sent to Sir James Graham, and to the college. In their letter to Sir James they said 'we earnestly believe that much benefit would be gained by the public were a legislative enactment made which should oblige parties proposing to practise as dentists to pursue a course of education similar to that followed by those intending to practise surgery and to gain for themselves a similar diploma. Evidence of patients suffering from the ignorance of parties who have not received any professional education, and yet practise as dentists, and who through advertisements delude the public by quackery and fraud, are constantly presenting themselves to our notice. Such gross imposition could not be practised by educated men as all must be who are qualified as surgeons. We confidently believe

${ }^{31}$ For full details of the history of this bill and proposed amendments to it see A. B. Erickson, The Public Career of Sir James Graham, Oxford, 1952 and 'An early attempt at medical reform in England: 1844-5', J. Hist. Med. All. Sci., 1950, 5, 144-55.

"I Hill, op. cit., p. 21.

"Ibid. 


\section{Dentistry in England in the 1840s}

that such an enactment would meet with the approbation of the public at large and of all respectable members of our branch of the profession . . . ${ }^{34}$ They noted also that in France, Germany, Austria and America those who practised as dentists were required to possess a certificate of qualification-in contrast no qualification was imperative in England. There appears to be no record of any answers to these letters, ${ }^{35}$ and Sir James Graham's Bill was in due course withdrawn-so nothing followed, either, from the appeal to him.

Hill sums up these efforts thus: 'their aim and object were laudable, their energy was indisputable, but their gatherings together were private and entirely devoid of authority'. ${ }^{36}$ Since no authority was possible by the very fact that no official professional authority existed which could speak for the profession, the 'severe spirit of caste and exclusiveness was often painfully manifest, and proved over and over again an obstruction to progress in the right direction'. ${ }^{37}$ The movement collapsed and a sullen quietude seems to have reigned-what was lacking was an able man to act as leader and a sufficient number of followers to take up the call.

The first number of the first journal devoted exclusively to the cause of dental science to be published in this country-the British Quarterly Journal of Dental Science-contains a pointed comment on the pleas to the College and to Sir James Graham and the provision of his bill, which neglected the dental issue-'a system of qualification, by education, and careful examination, is already in deference to public opinion diffusing itself throughout the various grades of medical practice; and for the future the public will, through the instrumentality of the Pharmaceutical Society, be enabled to protect itself, in a great measure, against the danger of receiving drugs from the hands of the ignorant and untaught druggist. Why should not the educated dentist be protected? Or rather, why, amid all these improvements in our social economy, is the public still to be left to the mercy of ignorant and dangerous pretenders to the art of dentistry?'38 Strong appeals were made in this new journal for an official recognition of dentistry and for a faculty of Surgeon-Dentists or College of Dentists. It stated its laudable aim in its first editorial column-'by a steady perseverance in this honest aim we may hope at last to be the instruments of so uniting our at present scattered profession, as that it shall come before the government of the country with a claim grounded in the strength of right, to be incorporated and to have power of instituting examinations, and granting diplomas to worthy candidates'. ${ }^{39}$

In further urging the need for the creation of a separate faculty of SurgeonDentists, Levison asks-'to what must we attribute our present position?' His answer was that "from the immense number of dentists and the competition in the charges for artificial teeth, the public has ceased to rank us as a profession and regard us as mere dealers.' ${ }^{10}$ The remedy suggested was to outlaw the quack, who was seen as 'a mean, ignorant, boasting personage who trusts to an unblushing impudence and

\footnotetext{
Quoted from Hill, op. cit., p. 26.

${ }^{85}$ Sir Zachary Cope, The History of the Royal College of Surgeons of England, London, 1959, p. 10.

s6 Hill, op. cit., p. 25.

${ }^{88}$ Brit. Quart. J. dent. Sci., 30 March 1843, p.65.

so Brit. Quart. J. dent. Sci., 30 March 1843, p. 3.

10 Brit. Quart. J. dent. Sci., 30 March 1843, p. 20.
} 


\section{N. David Richards}

showy dress and substitutes them for information and intellectual qualifications'. ${ }^{41}$

After only two numbers the British Quarterly Journal of Dental Science faded from the scene. In the following year, 1844, there appeared another dental periodical, the Forceps, which was to be published fortnightly from January 1844 to March 1845. Like its predecessor it was again founded by James Robinson; it attempted to stir dentists to take an interest in their profession. It suffered perhaps as a result of its editor's readiness to adopt a tongue-in-the-cheek attitude, and to provoke discussion between the different levels of practitioners. In retrospect it would seem that the time was not yet ripe for a dialogue between the two elements of the profession and over ten more years were to flow by before any further serious attempts were to be made to fuse together the various elements of the body of men who called themselves dentists.

Articles in the Forceps constantly underlined the need for dentistry to assume a higher position, for the establishment of an association or society of dentists and for the exposure of quackery in the interests of protecting the public. It forcibly pointed to the need for reform-'Dental Surgery has not, in this country, at least, assumed its proper position notwithstanding the vast improvements that have taken place, both in its principles and its details; it has been under peculiar disadvantages-practised indiscriminately by the educated and the empiric - by men of character and men of no character-by men of honour on the one hand, and men without a particle of honesty on the other. The profession, though it might properly be divided into two distinct classes, has, generally speaking, taken its grade from the lower: it depends on its other respectable members to raise it to its proper rank and estimation'.42 The immediate need was therefore for a restriction of practice- 'to do this it is essential that some public body be established possessing the moral power to weed it of the host of quackery by which it is at present overrun'. ${ }^{43}$ The present position in which dental surgery found itself was cause for concern, for 'when we look around and survey the improvements which have been effected in the various branches of science, we cannot, without some pain, contemplate the almost total neglect with which it seems the fashion to treat Dental Surgery . . . even the rank they [dentists] hold is not derived from being dentists but surgeons; as dentists they have no definite station'.44

It is clear that very few persons of this time appreciated the dentist's role; as a further editorial noted, 'from seeing low vulgar and ignorant men not only practise as dentists but do so publicly, drenching the papers with advertisements and hawking their valueless aid and worse goods with unblushing effrontery, the reputation of the art is deteriorated ... the fact is that the duties of, and the requisites for, a Dentist are little understood'.$^{45}$

Thus within certain elements of the body of dentists it was widely acknowledged that there was an urgent necessity for a reform of the dental profession; what was not so clear was however how this reform was to be effected, and by whose agencywhere indeed were its leaders to be found? Not it would seem amongst the aristocracy, who did not wish to pollute themselves by seeking contacts with those thought to be vulgar and disreputable. Nor indeed amongst the lower echelons, who were too

\footnotetext{
¿1 J. L. Levison, 'Exposure of quacks and quackery', Brit. Quart. J. dent. Sci., 30 June 1843, p. 83. 12 Forceps, 4 May, 1844, p. 69.

4 Forceps, 18 May 1844, p. 81 .

ts Ibid.

4s Forceps, 2 November 1844, p. 230.
} 


\section{Dentistry in England in the 1840s}

busied with making money for themselves, and who had little influence, being in active competition rather than co-operation with each other. What was needed was some form of association or union of dentists; as we have seen from the reception accorded to Waite's proposals, there was little possibility of action following an individual plea for reform. The Forceps considered 'there was no difficulty in forming an association of dentists, if twenty or thirty respectable members acted with unity of purpose'. ${ }^{46}$ The chasm which separated the two groups of practitioners was however not the only barrier, and even among the higher level of practitioners there was no commonly accepted bond of unity or purpose-'there is a certain jealousy among even the more respectable members of the profession which makes them view their brethren with distrust if not dislike'. ${ }^{77}$ The question was forcibly put-'does not the Dental Profession boast half a dozen men of character and energy to take the lead? Now is the time for action-miss it-the profession of Dentistry will sink into irretrievable infamy'.48

Quackery should, it was constantly underlined, be stamped out in the public interests - 'a host of impudent pretenders ready to sacrifice the best interests of society to their sordid cupidity, swarm like locusts on the land'. ${ }^{99}$ The public needed protecting, since 'few people among even the middle classes appreciate justly the importance of the operation of toothdrawing, and many who would shrink at the idea of going to a dispensary or an hospital, will, nevertheless, to save a mere trifle, which they could well afford, employ these cheap men'. ${ }^{50}$ The Forceps considered it was 'the duty, therefore, of the practitioners of the dental art to take steps as will at once protect themselves and the public, and the straightforward, and indeed only way to do this, is to form a society or an association'. ${ }^{51}$ The suggestion was not to form a monopoly but for 'fair and whole restrictions that will at once protect the interests of the profession and of the public, who at present cannot judge the competence of a dental practitioner until they have employed him, and many attribute the failures of ignorance to imperfections in the art itself rather than to the incompetence of men whom they believe accredited practitioners'. ${ }^{52}$

Beyond exposing the prevailing conditions and problems to be met and remedied, the effect of these high-minded proposals for reform was but slight. We may ask ourselves why this should be; it appears evident that laudable though the sentiments expressed in the Forceps were, they received but scanty circulation, and would, for the most part, have been read by practitioners who considered it beneath their dignity to deal directly with the inferior practitioners, with whom they considered they had little in common.

From these contemporary accounts it is possible to build a picture of the manner in which certain individual practitioners thought dentistry was regarded. There were however two grades of practitioners: on the one hand those surgeons who practised dentistry were held to be seceders by their fellow surgeons, and, on the other hand, these same persons regarded themselves as apart from the rank and file of the practitioners, many of whom, far from serving any articles of apprenticeship, went straight

\footnotetext{
${ }^{4}$ Forceps, 6 April 1844, p. 56.

${ }^{18}$ Forceps, 13 July 1844, p. 134

so Forceps, 27 July 1844, p. 141.
}

17 Forceps, 13 July 1844, p. 129.

19 Forceps, 20 April 1844, p. 57.

1 Forceps, 15 June 1844, p. 105. 


\section{N. David Richards}

out amongst the general public to seek patients who wanted a tooth drawing. It is not clear how many persons were actually practising dentistry at this period; it would appear however that it was only a matter of hundreds-indeed if this is an accurate estimation, then the numbers of the superior grade of practitioners, from whom it would have been more likely that a leader would have emerged, would have been small. It is therefore perhaps not too surprising that in spite of a strong plea for reform from certain quarters no direct action followed immediately. Medical services were themselves only now in the throes of full evolution - the development of dental services was not fully possible without the creation of a separate and organized dental profession. As we have seen, dental practitioners preferred at this time to stand alone.

The Forceps was in no doubt that dentistry was lagging behind other professions'there is no other profession so totally destitute of combination and consequently of influence. The Surgeons have their College, the Apothecaries their Hall, the Chemists their Pharmaceutical Society, the Artists their Royal Academy, and even the Veterinary Surgeons their College, but the Dentists seem to have no feelings in common-each practitioner stands isolated ... In this country any quack who chooses to place a brass plate on his door, some artificial masticators in his window, and advertises his list of charges in the papers is a dentist to all intents and purposes. What he may have been before is nothing; he may have spent his life as a watchmaker, a brewer's clerk or a milkman; he tells the public that he is a dentist and they are good-natured enough to believe him, and take his talents and capabilities for granted. These things must be reformed'. ${ }^{53}$ Despite the noble sentiments expressed in this missionary-spirited journal this view was like a lone voice crying in the desert and no action followed.

What then in summary were the principal factors acting at this time against any organization of the dental art? A first and important factor was the small number of practitioners, who at this period were to be counted, not in thousands but rather in hundreds. It is important also to remember the geographic isolation in which many dentists practised. Alexander Fothergill, looking back on changes in dentistry in the fifty-year period 1841-1891 commented, 'when my brother and I began to practice in this town [Darlington] we stood alone, and for many years we never saw nor had personal intercourse with any other dentists'. ${ }^{54}$

Further forces which tended to act against any organization or union of the dental profession were the lack of clear copying and printing facilities, and of communication. It was indeed only in these years that a national postal service was being developed and that the railway network was being built and expanded. Any professional organization had therefore really to be metropolitan rather than nationalbut even so no metropolitan alliance was evolved despite the efforts of such dentists as James Robinson, who in $\mathbf{1 8 4 2}$ had attempted to form a society of dentists. It would appear that there was insufficient pressure to induce action, and that many dentists seemed satisfied with things the way there were-indeed a growing urban population was producing an increasing volume of patients for treatment or, more exactly, for relief of pain. Those seeking for reform asked-'are the respectable

\footnotetext{
ss Forceps, 10 May 1844, p. 81.
}

s4 J. Brit. dent. Assoc., 1891, 12, 310 


\section{Dentistry in England in the 1840s}

practitioners so blind that they do not see what is known to half the world . . . are they content that their art should be considered a nonenity and their pretence to knowledge a cheat upon the public?'55 It seems indeed in retrospect, in view of the lack of subsequent action for a further ten years at least, that the profession was so blind.

Dentistry was at this stage relatively underdeveloped as a clinical specialism. Practitioners guarded their secrets of practice and technique, text-books were few, and formal teaching of the dental art was singularly lacking. Not only was there a sense of rivalry within the dental art, but also between those who practised surgery, and those who practised dental surgery-to some this latter group were viewed as seceders who had lost caste.

A further factor which prevented any organization was the barrier caused by differences in social origins, both of practitioners and of patients and in the levels of study, training and quality of service provided by those who called themselves dentists. Two contemporary accounts are to the point- there is no profession in which the highest and the lowest of its members stand at such extreme distances from each other as the practitioners of Dental Surgery ... At the bottom of the profession stands scattered a class of low ignorant shameless impostors, whose entire pretension is a mercenary lie .... at the top of the profession-we find a body of educated high minded men pursuing their career with honour to themselves and advantages to society'. ${ }^{56}$ 'There is no profession between the different members of which there is a greater distance as regards professional acquirements and private practice than Dental Surgery'. ${ }^{57}$

As earlier noted, absence of any natural or accepted leader was an additional factor responsible for the failure of any professional union to emerge at this period. John Tomes, to whom many eminent practitioners looked for their leader, was very much concerned with his research work during these years, and no other equally prominent personage was on hand to take the lead.

Dentistry suffered also because it was not generally practised as a speciality in the hospitals, in which formal courses in medicine and surgery were being established. The need for the medical student to acquire some knowledge of dental surgery was however underlined in the Forceps, which called for the appointment of dentists to all public hospitals, and dispensaries-'Diseases of the teeth are not confined, either to the paying orders or to the metropolis and large provincial towns, where dentists are more plentiful than blackberries in their suburbs, but occasionally affect inhabitants of the country, where they of necessity come under the care of the general practitioners, and the poor of the metropolis, who must go to a parish surgeon who knows little of the subject, or to a hospital, where the student knows less' ${ }^{58}$ Indeed one correspondent to the Lancet asked-'is it not desirable to appoint in every hospital a qualified dentist . . . I consider, by insisting upon the formation of chairs of dental surgery in each hospital our degraded profession will be brought to its proper position, and by the instrumentality of such lectureships we shall secure to our branch of science, and be the means, I expect, of founding a Dental College, where dentists

sorceps, 15 June 1844, p. 105.

67 Forceps, 13 July 1844, p. 129.

\footnotetext{
Forceps, 18 May 1844, p. 81.

${ }^{6}$ Forceps, 10 February 1844, p. 17.
} 


\section{N. David Richards}

may pass an examination to become respected members of our rising and important profession'. ${ }^{59}$

The Report of the Sanitary Condition of the Labouring Population of Great Britain, published in 1842, drew attention to the chaotic state of local government, cleansing and sewering. There followed in 1848 through the Public Health Act the first affirmation of the state's responsibility for securing minimum conditions of health for the people. The chaos of squalid living and unregulated urban development was forthwith to be attacked-the ravages of dental disease were however left to await attention. The accent for improvements in health matters was placed upon an attack on the isolation, and prevention of epidemics and of infectious and communicable diseases: dental disease, being but rarely a killer, was of considerably less priority and far from being the subject of a public or governmental agitation for an amelioration in the services provided. For one thing, little was known of the numbers of persons who at this time were in need of some dental operation-indeed this is a general comment which might be made of the extent and gravity of many of the prevailing social problems, for without some index of measurement there was little or no evidence to suggest what reforms were needed. Nevertheless the climate of reform manifested itself in a number of ways following the introduction of more scientific surveying and measurement of conditions and the collection of death, public health and census statistics. More concrete evidence now became available and a period of experimentation was begun with the various attempts to facilitate reform. The forces of Utilitarianism and Chartism produced elements in Victorian society which became more reform-conscious and which strove to evolve a utopian society by eradicating social evils and injustices.

The need for reform within the dental art was however not translated into direct action and despite numerous suggestions for change the total achievement resulting from all these ideas was nil. The factors which operated against change and reform were, as we have seen, too strong and they prevented any systematic organization of dentistry-without this organization dental services were stifled and failed to develop on any planned lines. So too did dental education and no formal or standardized training courses were possible. With the apprenticeship system, such as it was, the curriculum had to be elastic, and, as a result of the lack of any recognized standards, the dentist suffered and came to be seen as one of an ill-defined class of practitioners hovering on the fringe of what was regarded as respectable surgery. Clearly he had still to prove himself, and the services he offered, to the community.

Dentistry was then, in the middle of the last century, in the condition of a foundling. According to Sercombe, amongst dentists 'were to be found men whose writings may be regarded as amongst the professional classes . . . and at the opposite pole there were men who could scarcely read or write'. ${ }^{60}$ Charlatanism was indeed rampant and dentists were accorded a low status, as was made clear by James Robinson, who had become dentist to the Royal Free Hospital, London. In an address to the Society of the Alumni of the Baltimore College of Dental Surgery, he noted that 'the anomalous

so Letter from James I. Keene, Lancet, 1851, ii, 263.

Bo E. Sercombe, Presidential Address to the Odontological Society of Great Britain, Trans. odont. Soc., 1873-4, New Series 6, 125 . 


\section{Dentistry in England in the 1840s}

position which Dental Surgery occupies in England is much to be regretted, ${ }^{61}$ and that 'Falstaff himself never possessed a more heterogeneous nondescript army than those who composed the majority of dentists in England. Having failed in every other department they consider themselves perfectly competent to practice as dentists' ${ }^{62}$ He referred to the indignity which respectable and educated practitioners were forced to endure, and commented thus - 'the adage that any fool will do for a parson may be applied with still greater force and truth to the profession of a dentist'. ${ }^{63}$

Robinson's address published in 1850, provides yet a further cameo-picture of the contemporary dental scene; nevertheless, as he himself observes, 'a biographical living sketch-book of the dental practitioners of England would form a curious and interesting melange, and would show the incongruous materials of which the craft is composed. We should have blacking-merchants, Jew clothesmen, Jew bill-discounters, policemen, horse-dealers, milkmen, broken-down doctors and apothecaries, rejected medical pupils cum multis alis. The more ignorant and unscrupulous among them adopt some high-sounding French or jaw-breaking German name . . . and shroud their grub-like origin in the butterfly hues of a flaunting equipage and flaring liveries to dazzle the eyes while they empty the pockets of their dupes. Such is the varied character of the dental profession in England, which boasts of her wealth, her civilisation, and intelligence, while she bows down before the meretricious shrine of quackery and humbug. ${ }^{64}$ Robinson comments on differences between the dental profession in England and the United States and pointedly again refers to the need for professional organization in England-'a dark cloud overhangs the profession, and involves even the most eminent and distinguished in its shadow. High as their social rank or professional attainments may be, they are open to the imputation of having made no effort collectively or individually to imitate the noble example set them by the dentists of the United States, and form an association or society of the leading men of their body, and by united exertion rescue the profession from its present questionable and somewhat equivocal position'. ${ }^{65}$

These were the dark ages for dentistry; several optimistic signs were however already appearing on the horizon, and certain far-seeing individuals were advocating a reform of the prevailing chaos in dental affairs. It appeared though that the climate was not yet favourable enough for action to follow so swiftly after the pleas for reformation, and reorganization. Parmly, writing of the need for dental reform in North America-his words are however equally applicable to the dental scene in this country-commented thus: 'from impostors and swindlers, men without honour and moral obligation, we can expect no reform. They will be impostors and swindlers still'. ${ }^{66}$ The reader will thus appreciate the sombre background against which these developments were taking place-charlatanism, like a fungus, was thriving in this darkness, and dentistry was still awaiting its reformers, who were to elevate and organize the speciality on a more sure footing. The prevailing attitude of mind of those who strove for reform was well put by C. Smartt of Bishopsgate-'how much higher would be the position of the dentist than it is, could he be severed from the penny

61 Amer. J. dent. Sci., 1850, 10, 227

os Ibid.

os Amer. J. dent. Sci., 1850, 10, 245.
62 Ibid.

${ }^{6}$ Amer. J. dent. Sci., 1850, $10,239$.

os Amer. J. dent. Sci., 1842, 3, 1. 


\section{N. David Richards}

barber and the village blacksmith' ${ }^{67}$ The tide had however been turned, and a new wave of reform was to follow shortly; indeed as the Forceps noted: 'we have conjured up a spirit of inquiry and a demand for improvement, that, in spite of apathy on the one hand, and the opposition of interested cupidity on the other, will not be laid until the professors of dental surgery have assumed their proper and legitimate stations'. ${ }^{68}$

Despite the asseverations of such men as Waite, Levison and Robinson the movement for reform remained acephalous and amorphous. Over ten more years were to flow by before any natural leaders emerged to mould together and establish the first organized professional associations-the Odontological Society of London and the College of Dentists. Reform was on the way, but it was indeed the first steps towards change that were to prove troublesome.

77 Letter in Lancet, 1850, ii, 514.

${ }^{68}$ Forceps, 11 January 1845, p. 6. 